\title{
Welfare Assessment Based on Metabolic and Endocrine Aspects in Primiparous Cows Milked in a Parlor or with an Automatic Milking System*
}

\author{
F. Abeni, ${ }^{1}$ L. Calamari, ${ }^{2}$ F. Calza, ${ }^{1}$ M. Speroni, ${ }^{1}$ G. Bertoni, ${ }^{2}$ and G. Pirlo ${ }^{1}$ \\ ${ }^{1}$ Consiglio per la Ricerca e Sperimentazione in Agricoltura, Istituto Sperimentale per la Zootecnia, \\ Sezione Operativa di Cremona, I-26100 Cremona, Italy \\ ${ }^{2}$ Istituto di Zootecnica, Facoltà di Agraria, Università Cattolica del Sacro Cuore, I-29100 Piacenza, Italy
}

\begin{abstract}
An automatic milking system (AMS) was compared with a traditional milking parlor (MP) to evaluate metabolic and psycho-physiological aspects of animal welfare. Twenty Italian Friesian heifers were allocated to 2 groups of 10 cows each after calving and maintained in the same free-stall barn. The first group was milked twice daily in a MP; the second group was milked in a single box AMS. Feed and diet characteristics were analyzed. Health status and body condition score (BCS) were evaluated in each cow. Blood samples were obtained from -14 to $154 \mathrm{~d}$ in milk (DIM) to determine metabolic profile and basal concentrations of cortisol in plasma. Data collected from 10 cows per group were processed. No significant difference was detected in milk yield, BCS, and energy-related metabolites (glucose, nonesterified fatty acids, $\beta$-hydroxybutyrate, and triglycerides) from cows in MP or in AMS during the first 22 wk of lactation. These results, jointly with the absence of significant differences in plasma metabolites related to protein metabolism, mineral metabolism, and liver function during the first 22 wk of lactation, indicates that cows in AMS did not suffer metabolically. Greater basal concentrations of plasma cortisol in AMS cows, even if absolute values were considered to be in an acceptable range, might indicate chronic stress in these primiparous cows. Further research is necessary to confirm this hypothesis.
\end{abstract}

(Key words: automatic milking, blood metabolite, cortisol, welfare)

Abbreviation key: AMS = automatic milking system, AP = alkaline phosphatase, AST = aspartate aminotransferase, ECM = energy-corrected milk yield, GGT =

\footnotetext{
Received December 2, 2004.

Accepted June 9, 2005.

Corresponding author: F. Abeni; e-mail: fabio.abeni@isz.it.

*This research was conducted under a grant from the Ministry of Agriculture and Forestry Policies, Italy (Finalized project: "Total automation of dairy barn").
}

$\gamma$-glutamyltransferase, $\mathbf{L D H}=$ L-lactate dehydrogenase, $\mathbf{M P}=$ milking parlor, $\mathbf{P C V}=$ packed cell volume .

\section{INTRODUCTION}

The automatic milking system (AMS) relieves dairy producers of labor-intensive routines of the traditional milking parlor (MP; Mathijs, 2004). A growing concern about animal welfare, however, requires an evaluation of the impact of this new technology on cow health, physiology, and behavior (Hillerton et al., 2004). Both negative and positive animal welfare consequences arising from AMS introduction may be hypothesized. Two kinds of factors should be considered in the evaluation of cow welfare under AMS conditions: 1) psychophysiological aspects related to disruption of social behavior rather than problems caused by the interaction between animal and machine and 2) metabolic aspects related to a possible increase in nutrient demand rather than a different feeding behavior in comparison with a MP system. For example, disruption of the cow's social behavior when milking becomes an individual rather than a social activity could have a negative outcome (Wiktorsson and Sørensen, 2004). Conversely, one positive effect could be the cow's free choice to enter the milking unit when it needs to eat concentrate and the fact that it can then be milked (Wiktorsson and Sørensen, 2004).

Furthermore, rolling herd average milk production is almost $15 \%$ greater for herds milking $3 \times / \mathrm{d}$ than for herds milking $2 \times / \mathrm{d}$ (Smith et al., 2002). The AMS allows a voluntary increase in milking frequency, which could increase milk yield from 3 to $11 \%$ over the common twice-daily milking strategy (Baines, 2002; de Koning et al., 2002; Wade et al., 2004). Increase in milk yield from increased milking frequency is essentially caused by local control of milk secretion. More milk is secreted because chemical and physical inhibitory mechanisms are less invoked (Knight et al., 1998). One matter of concern is whether cow metabolism is able to support related increases in nutrient requirement by means of mobilized body reserves. 
Wiktorsson et al. (2003), investigating some physiologic and metabolic aspects of the cow in an AMS throughout the first $19 \mathrm{wk}$ of lactation, showed that primiparous cows may experience a severely negative energy balance in early lactation, with a greater body tissue mobilization than that in older cows, when a high milking frequency occurs in the AMS. Recently, Wenzel and Nitzschke (2004) studied the incidence of ketosis and reported no differences in serum glucose, $\beta$ hydroxybutyrate, urea, and aspartate aminotransferase (AST) for cows milked in a MP vs. an AMS.

Cows exposed to an AMS may have a possible decrease in nutrient balance during early lactation, but also a different pattern of some plasma metabolites from those milked in a MP as a consequence of the differences in feeding behavior between the 2 milking systems (Olofsson et al., 2000; Wagner-Storch and Palmer, 2003). In a behavioral study, feeding activity increased after milking and feed delivery for parlor cows, whereas milking and feeding activity in the AMS increased after human intervention (Wagner-Storch and Palmer, 2003). Olofsson et al. (2000) reported that feed intake was less during the night for cows in an AMS. Differences in feeding behavior (i.e., low nighttime feeding activity in AMS) might lead to differences in the plasma metabolites (i.e., increased plasma NEFA in early morning as a consequence of long night-time feed withdrawal). In addition, socially low-ranked animals spent less time in the feeding area and made fewer visits to the feeding stations (Olofsson and Svennersten-Sjaunja, 2004), increasing their average interval between meals.

The hypothesis that milk yield increases because of AMS, together with insufficient information in AMS field trials, justifies specific research on these metabolic aspects. Blood metabolites considered in a metabolic profile may provide information on energy and protein metabolism, and together with BCS and milk yield, might show changes in lipid mobilization (Bertoni et al., 1999). Minerals, plasma proteins, and enzymes also could be useful to show whether inflammatory conditions occur or whether hepatic function and digestive processes are affected by husbandry (Bertoni et al., 1999).

With regard to the psycho-physiological aspects, the milking process represents a source of factors that may be stressful for naive primiparous cows, including novelty and interaction with a human (as in MP) or a mechanical robotic system (as in AMS), which might alter plasma cortisol, a glucocorticoid hormone related to stress response. Milking cows in an unfamiliar environment results in elevated concentrations of plasma cortisol, elevated heart rates, reduced oxytocin release, and less milk yields concomitant with an increase in the fraction of residual milk (Bruckmaier et al., 1993; Rushen et al., 2001). Cortisol itself does not seem to influence central inhibition of milk ejection (Wellnitz and Bruckmaier, 2001). In a previous study of primiparous cows, AMS produced baseline concentrations of plasma cortisol similar to those of cows milked in a MP (Hopster et al., 2002). Cortisol is widely considered to be a marker of stress in cattle. Baseline concentrations of plasma cortisol may be of interest to verify whether the milking system per se can affect the cow's susceptibility to suffer stress. Cortisol patterns in a chronic stress situation, however, are often controversial, especially when social hierarchy is taken into account (Wiktorsson et al., 2003).

The objective of this study using primiparous cows was to compare the effects of the milking system and related milking frequency on the susceptibility to metabolic stress and to psycho-physiological chronic stress in cows milked in a MP or by an AMS.

\section{MATERIALS AND METHODS}

\section{Animals and Husbandry}

Twenty healthy Italian Friesian first-lactation cows were chosen to study differences resulting from milking in a MP vs. an AMS. Two months before calving, heifers were allocated to 2 groups of 10 cows each that were comparable in terms of average breeding value, expected age at first calving, expected calving season, and BCS (Edmonson et al., 1989). At the beginning of lactation, the cows were introduced into 2 similar herds, each composed of a total of 50 cows, which were also comparable for average milk yield and parity. Ten firstlactation cows in each herd were selected from among those that had not experienced calving-related disorders, to study animal welfare mainly through metabolic and endocrine aspects during the first half of lactation.

Both herds were housed in the same free-stall barn. A double-8 herringbone MP was located at 1 end of the barn and at the other end was located a single box AMS (DeLaval VMS; DeLaval, Tumba, Sweden). Both groups of cows were fed a similar TMR distributed once daily $(0800 \mathrm{~h})$. The AMS cows also received a concentrate supply in the milking stall: $1 \mathrm{~kg} / \mathrm{d}$ for every $10 \mathrm{~kg}$ of daily milk yield. Concentrate supplied in the milking stall had a chemical composition similar to that of the TMR (Table 1). The MP cows received additional concentrate supplied in the TMR ranging from 0.5 to 1.5 $\mathrm{kg} / \mathrm{d}$; the TMR was provided at the planned DMI level for the cows of the 2 groups, which allowed for a balance in average energy and protein intake between the 2 groups (Table 1). Routine milking times in the parlor started at 0530 and at $1630 \mathrm{~h}$. Ingredients of the TMR in both groups are reported in Table 1. 
Table 1. Ingredient and chemical composition and nutritive value (on DM basis) of TMR fed to cows milked in a traditional milking parlor or in a single box automatic milking system (AMS).

\begin{tabular}{lcc}
\hline & \multicolumn{2}{c}{ Milking system } \\
\cline { 2 - 3 } Ingredient & Parlor & AMS $^{1}$ \\
\hline & $-(\%$ of $\mathrm{DM})-$ \\
Fescue hay & 8.6 & 9.6 \\
Alfalfa hay & 7.8 & 7.2 \\
Corn silage & 33.2 & 34.0 \\
Cottonseed whole & 8.1 & 8.1 \\
Corn grain (70\% ground and $30 \%$ steam flaked) & 22.2 & 21.1 \\
Commercial protein concentrate ${ }^{2}$ & 19.2 & 19.1 \\
Vitamin and mineral premix ${ }^{3}$ & 0.9 & 0.9 \\
Chemical & & \\
CP & 15.10 & 14.90 \\
Ether extract & 4.78 & 4.77 \\
NDF & 32.77 & 33.23 \\
ADF $_{\text {Starch }}$ & 20.26 & 20.71 \\
NE $_{\mathrm{L}}{ }^{4}{ }^{2}$ Mcal/kg of DM & 27.61 & 27.05 \\
\hline
\end{tabular}

${ }^{1}$ Cows in the automatic milking system also received a concentrate supply in the milking stall ( $1 \mathrm{~kg} / \mathrm{d}$ for every $10 \mathrm{~kg}$ of daily milk yield). One kilogram of DM contained $177 \mathrm{~g}$ of $\mathrm{CP}, 37 \mathrm{~g}$ of ether extract, $292 \mathrm{~g}$ of NDF, $120 \mathrm{~g}$ of $\mathrm{ADF}$, and $245 \mathrm{~g}$ of starch.

${ }^{2}$ One kilogram contained $12 \mathrm{~g}$ of $\mathrm{Ca}, 7.8 \mathrm{~g}$ of P, $23 \mathrm{mg}$ of $\mathrm{Fe}, 6 \mathrm{mg}$ of $\mathrm{Cu}, 110 \mathrm{mg}$ of $\mathrm{Mn}, 0.3 \mathrm{mg}$ of $\mathrm{Co}, 165 \mathrm{mg}$ of $\mathrm{Zn}, 0.9 \mathrm{mg}$ of I, 0.11 $\mathrm{mg}$ of Se, 45,000 IU of vitamin A, $2000 \mathrm{IU}$ of vitamin D3, and $65 \mathrm{mg}$ of vitamin $\mathrm{E}$.

${ }^{3}$ One kilogram contained $145 \mathrm{~g}$ of $\mathrm{Ca}, 70 \mathrm{~g}$ of $\mathrm{P}, 1350 \mathrm{mg}$ of $\mathrm{Fe}$, $400 \mathrm{mg}$ of $\mathrm{Cu}, 2500 \mathrm{mg}$ of $\mathrm{Mn}, 50 \mathrm{mg}$ of $\mathrm{Co}, 5000 \mathrm{mg}$ of $\mathrm{Zn}, 115 \mathrm{mg}$ of I, $20 \mathrm{mg}$ of Se, 1,000,000 IU of vitamin A, 150,000 IU of vitamin $\mathrm{D} 3$, and $5000 \mathrm{mg}$ of vitamin $\mathrm{E}$.

${ }^{4}$ Determined using NRC (2001) values.

In the AMS area, selectively forced cow traffic (Harms et al., 2002) was applied. The feeding area was separated from the resting area by one-way gates, which allowed free access of cows to free stalls without being milked. Cows were obligated, however, to pass the AMS area before entering the feeding area, with a bypass consisting of a preselection gate. Cows recently milked $(<5 \mathrm{~h}$ earlier, with the exception of passages after an incomplete milking) were not obligated to pass through the milking stall and the waiting area in front of it but were deviated directly to the feeding area; others were admitted to the milking stall (Figure 1). The AMS was always accessible except during cleaning at 0400, 1200, and $2000 \mathrm{~h}$ for about 30 min each time. Any cow not milked during the last $12 \mathrm{~h}$ was directed to the AMS $(0530$ and $1730 \mathrm{~h})$ to avoid milking intervals $>12 \mathrm{~h}$. Health disorders of each cow were recorded and classified during the trial.

Milk yield was recorded continuously in the AMS, using a daily mean calculated on 4 consecutive $d$ to represent one week for statistical analysis, whereas milk yield in the MP was recorded weekly (for 2 consecutive milkings).
Data on traffic of the 10 cows were obtained from the recorded passages through the preselection gate and in the milking unit.

\section{Sampling}

A representative sample of each feed was taken at every batch change to estimate compositional analyses and nutritive value.

Blood samples were obtained before the morning distribution of TMR at $0730 \mathrm{~h}$. Blood was collected at -14 , $1,7,14,28,42,70,98$, and $154 \mathrm{~d}$ relative to calving. At the same schedule, BCS was evaluated for each cow. A single blood sample was collected from the jugular vein via venipuncture using $10-\mathrm{mL}$ Li-heparin Venoject tubes (Terumo Europe, Leuven, Belgium). Blood samples were immediately placed in an ice bath, where they were stored until processed approximately 30 min later. Packed cell volume (PCV) was determined using a hematocrit centrifuge; then, plasma was separated by centrifugation $(2850 \times g$ for $20 \mathrm{~min})$. Four subsamples were stored frozen at $-20^{\circ} \mathrm{C}$ until analyzed.

Milk composition was determined monthly on individual daily composed milk to obtain milk fat and protein contents and to calculate energy-corrected milk yield (ECM).

\section{Laboratory Analyses}

Feedstuffs were analyzed for DM, CP, crude fiber, $\mathrm{NDF}$, ether extract, ash, and starch content (Martillotti et al., 1987). Values of $\mathrm{NE}_{\mathrm{L}}$ were estimated according to the NRC (2001).

Blood metabolites were analyzed at $37^{\circ} \mathrm{C}$ by clinical analyzer (ILAB 600; Instrumentation Laboratory, Lexington, MA). End-point analysis for glucose, urea, calcium, inorganic phosphorus, magnesium, total protein, albumin, total bilirubin, and creatinine were conducted using commercial kits (Instrumentation Laboratory, Lexington, MA) and for Zn by using a commercial kit (Wako Chemicals GmbH, Neuss, Germany). Enzymatic end-point analyses for total cholesterol and triglycerides were conducted using commercial kits (Instrumentation Laboratory, Lexington, MA) and for NEFA by using a commercial kit (C-Test Wako; Wako Chemicals $\mathrm{GmbH})$. Kinetic analyses to determine activity of alkaline phosphatase (AP; EC 3.1.3.1), aspartate aminotransferase (AST; EC 2.6.1.1), $\gamma$-glutamyltransferase (GGT; EC 2.3.2.2), and L-lactate dehydrogenase (LDH; EC 1.1.1.27) also were conducted using commercial kits (Instrumentation Laboratory, Lexington, MA). A potentiometric system, with specific electrodes, was used to determine $\mathrm{Na}, \mathrm{K}$, and $\mathrm{Cl}$. Ceruloplasmin, haptoglobin, and BHBA were determined with reagents prepared 


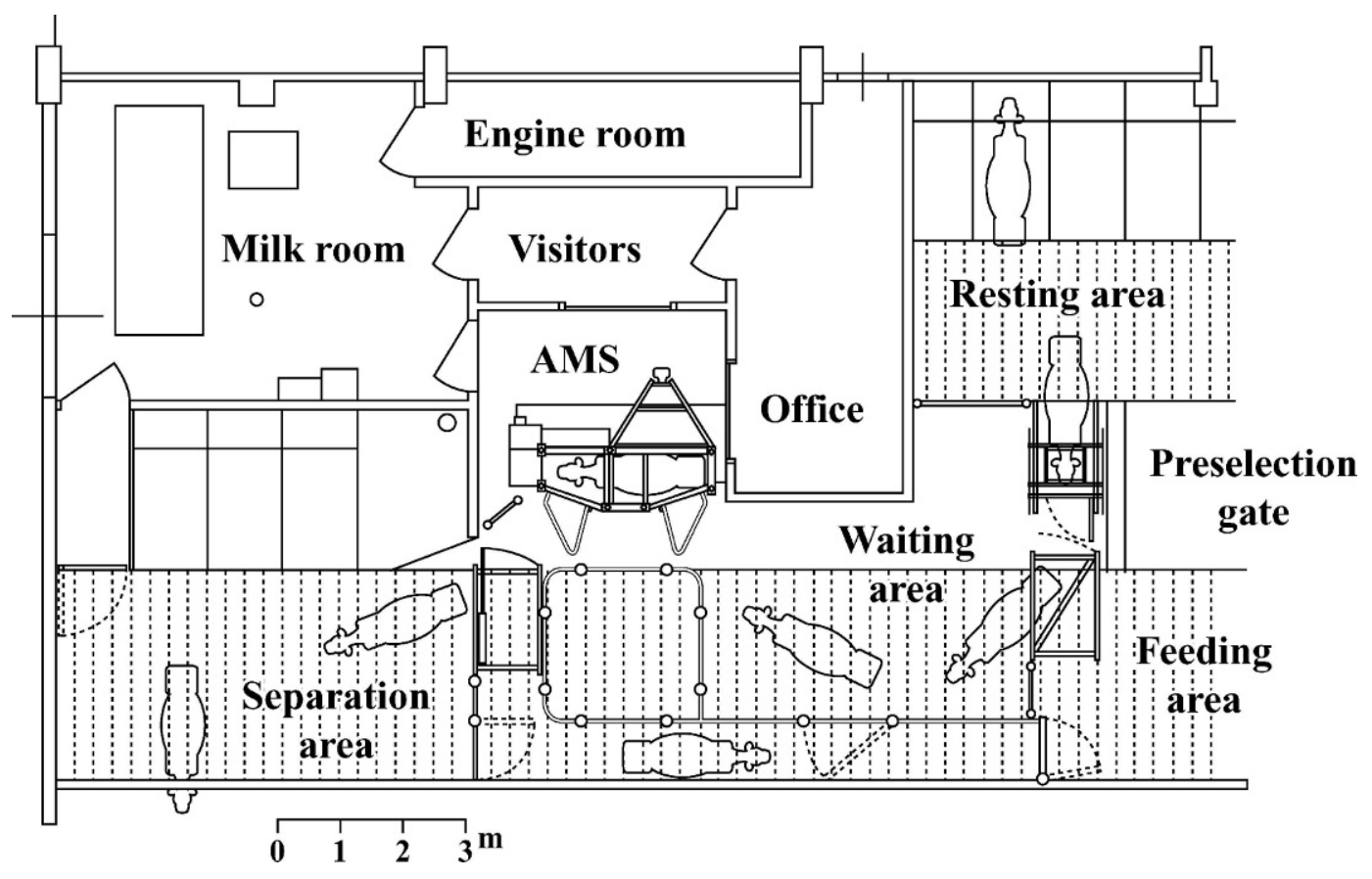

Figure 1. Layout of the automatic milking barn (AMS = automatic milking system).

according to Bertoni et al. (1998). Plasma cortisol was analyzed using a commercial kit for radioimmunological assay (SORIN SpA, Vercelli, Italy), using the method modified by Bertoni et al. (2002).

Contents of fat and protein in milk were determined with an infrared analyzer (Bertoni et al., 1998).

\section{Statistical Analyses}

Normal distribution of blood metabolites was tested by using the Shapiro-Wilk test before further analyses. Therefore, the following variables were log transformed: triglycerides, NEFA, BHBA, creatinine, ceruloplasmin, haptoglobin, AST, GGT, AP, LDH, bilirubin, and cortisol. Main effects of milking system, DIM, and milking system $\times$ DIM were determined by using the MIXED models procedure of SAS (SAS Inst., Inc., Cary, $\mathrm{NC}$ ), in which prepartum values were used as covariates. Where repeated measures were assessed, cow was the "subject" in the MIXED model procedure to account for correlations of measures within animal. A compound symmetry structure of covariance was selected on the basis of the results from fit statistics Akaike's information criteria and Bayesian information criteria. Least squares means $( \pm \mathrm{SEM})$ were generated and reported herein for selected variables. When a significant $(P \leq$ $0.05) F$ test was detected, interactions were evaluated using the PDIFF option in SAS.

Separate analyses for plasma NEFA and BHBA were conducted within AMS to evaluate the effect of the in- terval between blood sampling and the most recent meal. Two classes of time intervals between the most recent meal and blood sampling were identified: $\leq 3$ and $>3 \mathrm{~h}$. Only data from $7,14,28$, and 42 DIM were considered in these analyses. Main effects of time interval, DIM, and time interval $\times$ DIM were determined by using the MIXED model procedure of SAS (SAS Inst., Inc., Cary, NC). As before, cow was used as the "subject" for the MIXED procedure.

The same statistical procedure was used to analyze milk yield. The only difference was a larger number of observations in time (each week from calving to the 22nd week of lactation), and no covariate was incorporated in the model.

\section{RESULTS}

\section{Milk Yield}

To better understand cow traffic in the AMS, Figures 2 and 3 illustrate the following descriptive graphics: diurnal pattern of milkings (Figure 2a), diurnal pattern of total passages through the preselection AMS gate (Figure 2b), frequency distribution for classes of intervals between passages through the milking stall (Figure $3 \mathrm{a}$ ), and intervals between passages through the preselection gate (Figure 3b). In these figures, times of TMR distribution, cow fetching, and AMS cleaning are reported. From Figure 2, it seems that night-time feeding activity was less than daytime feeding activity, as 

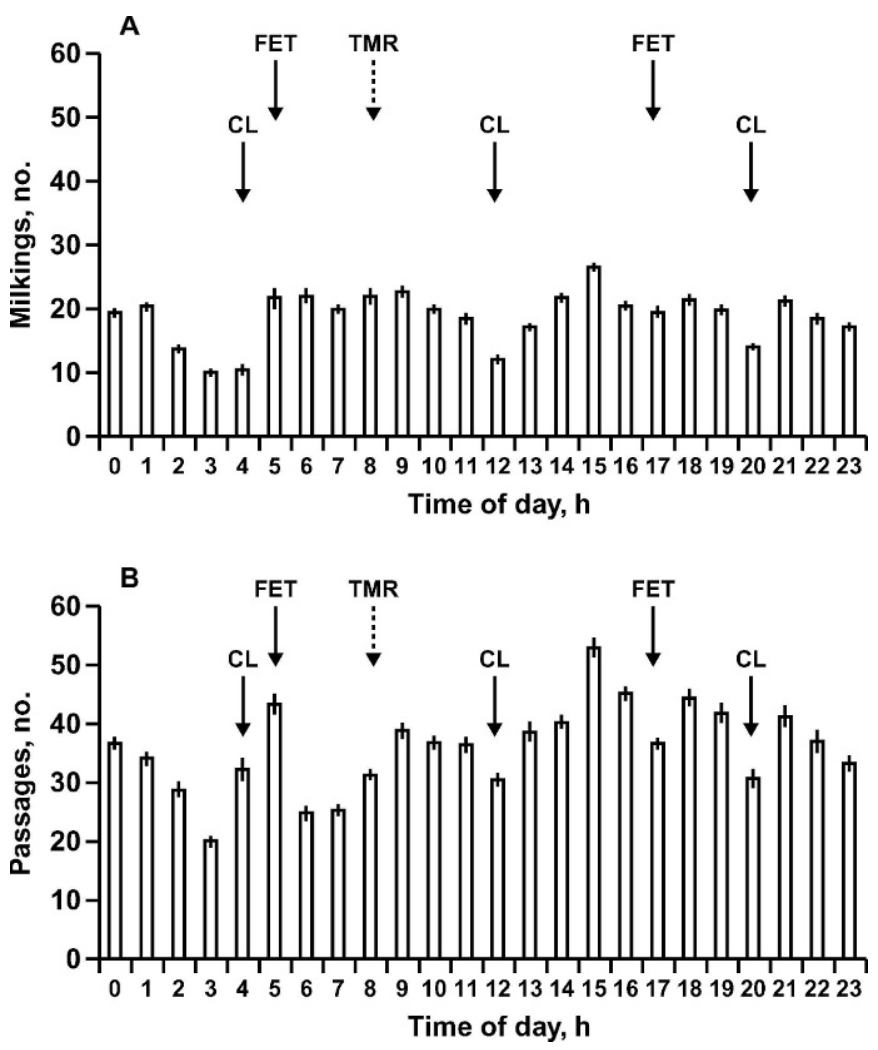

Figure 2. Diurnal pattern of a) milkings and b) total passages through the preselection gate in the automatic milking system (AMS). Values are expressed as total number per cow during the first 154 DIM. Arrows indicate time of TMR distribution (TMR), time of cow fetching (FET), and cleaning time (CL). Vertical lines at the top of the bars represent SEM.

demonstrated by reduced cow passage rate through the preselection gate. In fact, between 0800 and $2000 \mathrm{~h}$, $55 \%$ of total passages occurred, compared with $45 \%$ between 2000 and $0800 \mathrm{~h}$. The class with the larger frequency of intervals between passages through the milking stall was between 7 and $8 \mathrm{~h}$ (Figure 3a), and $>60 \%$ of milkings occurred at intervals ranging between 6 and $9 \mathrm{~h}$. The class with the larger frequency of intervals between passages through the preselection gate was between 3 and $4 \mathrm{~h}$ (Figure 3b), and $>70 \%$ of passages through the preselection gate occurred at intervals $<5 \mathrm{~h}$.

No difference in milk yield was detected between milking systems during the first $22 \mathrm{wk}$ of lactation. No interaction was detected between milking system and DIM (Figure 4). No difference was detected in ECM between cows in MP and AMS (30.5 vs. $30.4 \mathrm{~kg} / \mathrm{d}$, respectively), during the first $22 \mathrm{wk}$ of lactation. No interaction was detected between milking systems and DIM. Milking frequency for 10 cows in AMS averaged 3.0 \pm 0.5 milkings/d in the first 154 DIM (Figure 4). Night-
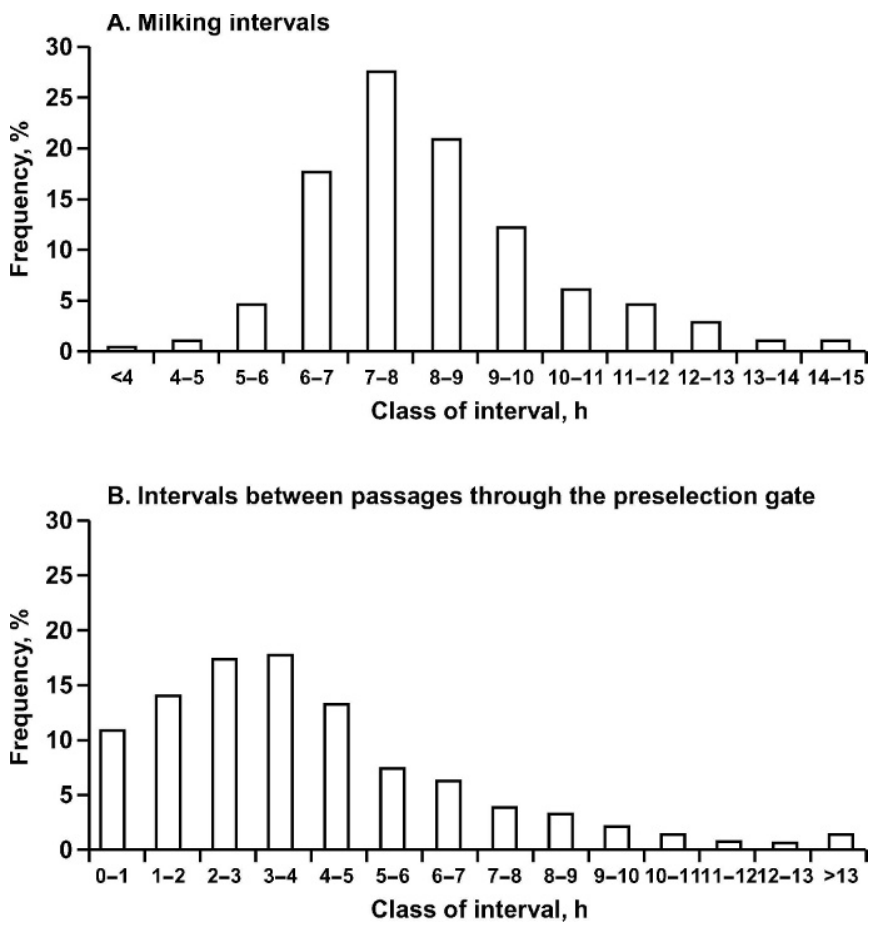

Figure 3. Frequency distribution for classes of intervals a) between passages through the milking stall and b) between passages through the preselection gate in the automatic milking system (AMS) during the first 154 DIM for the 10 cows.

time feeding activity was less than daytime feeding activity, as was demonstrated by the reduced cow passage rate through the preselection gate. In fact, between 0800 and $2000 \mathrm{~h}, 67 \%$ of total passages through the preselection gate directly to the feeding area took place, compared with $33 \%$ between 2000 and 0800 h. During the same time periods, milkings were 54 and $46 \%$, respectively.

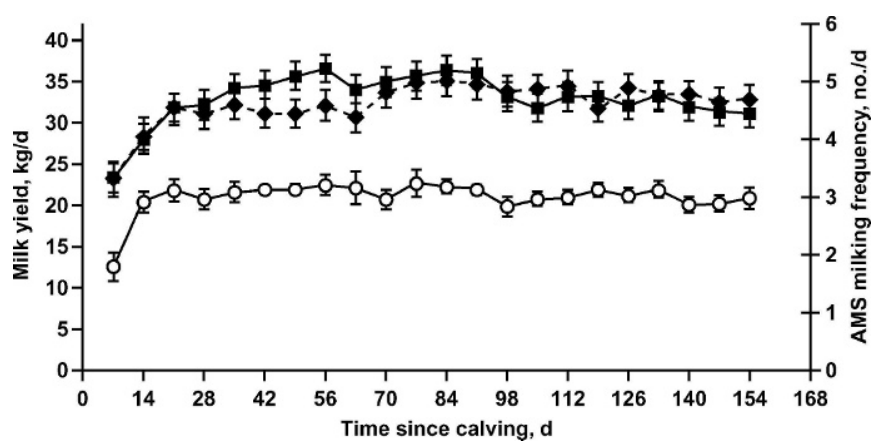

Figure 4. Least squares means $( \pm \mathrm{SE})$ of daily milk yield $(\mathrm{kg} / \mathrm{d})$ during the first 154 DIM for cows managed in a traditional milking parlor system (MP; ) or in an automatic milking system (AMS; $\mathbf{\square})$. Milking frequency of AMS heifers was reported as the average value calculated from $4 \mathrm{~d} / \mathrm{wk}(\mathrm{O})$. 


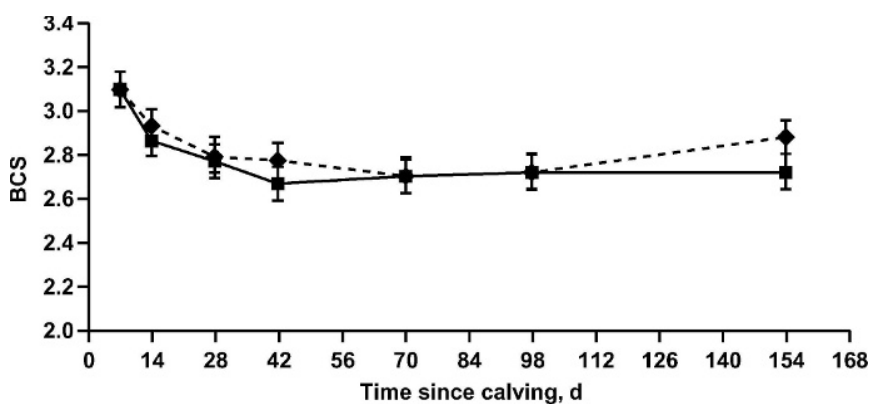

Figure 5. Least squares means ( \pm SE) of BCS during the first 154 DIM for cows managed in a traditional milking parlor system (MP; $\checkmark)$ or in an automatic milking system (AMS; $\mathbf{\square})$.

\section{BCS and Energy Metabolism}

Metabolic conditions at calving were used only to check whether cows had metabolic disorders related to late pregnancy; they were not included for statistical evaluation because they are strongly influenced by the time interval between calving and bleeding.

No difference was detected in BCS of cows between the 2 milking systems. Both groups had similar changes in BCS after calving (Figure 5). Before calving, BCS was $3.4 \pm 0.1$ in both groups. Cows in MP had the least BCS at 70 DIM and tended to have a faster rate of recovery, whereas cows in AMS had the least BCS at 42 DIM and tended to have a slower rate of recovery, even when no differences were detected at 154 DIM.

No differences between cows exposed to the 2 milking systems were detected in plasma concentrations of glucose, NEFA (Figure 6a), BHBA, triglycerides, and cholesterol (Figure 6b), nor were interactions between milking systems and DIM observed (Table 2). Total cholesterol gradually increased $(P<0.05)$ from calving to $98 \mathrm{DIM}$ in both groups (Figure $6 \mathrm{~b}$ ).

In contrast, within AMS cows, intervals between the last meal and blood sampling altered $(P=0.001)$ plasma NEFA. An interaction $(P=0.003)$ was detected between milking system and DIM. Specifically, cows having no passages to the feeding area during the $3 \mathrm{~h}$ preceding blood sampling had greater $(P=0.001)$ plasma NEFA than those that passed through the milking unit or through the preselection gate to the feeding area during the $3 \mathrm{~h}$ preceding blood sampling (602 vs. $406 \mu \mathrm{mol} / \mathrm{L}$, respectively; Figure 7a). Differences $(P<0.001)$ within DIM occurred at $42 \mathrm{DIM}$ (517 vs. $174 \mu \mathrm{mol} / \mathrm{L}$, respectively). These differences in plasma NEFA did not lead to differences in plasma BHBA (542 vs. $490 \mu \mathrm{mol} / \mathrm{L}$, respectively; Figure 7b).

\section{Protein Metabolism, Inflammatory Response, and Liver Activity}

No differences were found in plasma concentrations of urea and creatinine (Table 2). Plasma urea increased
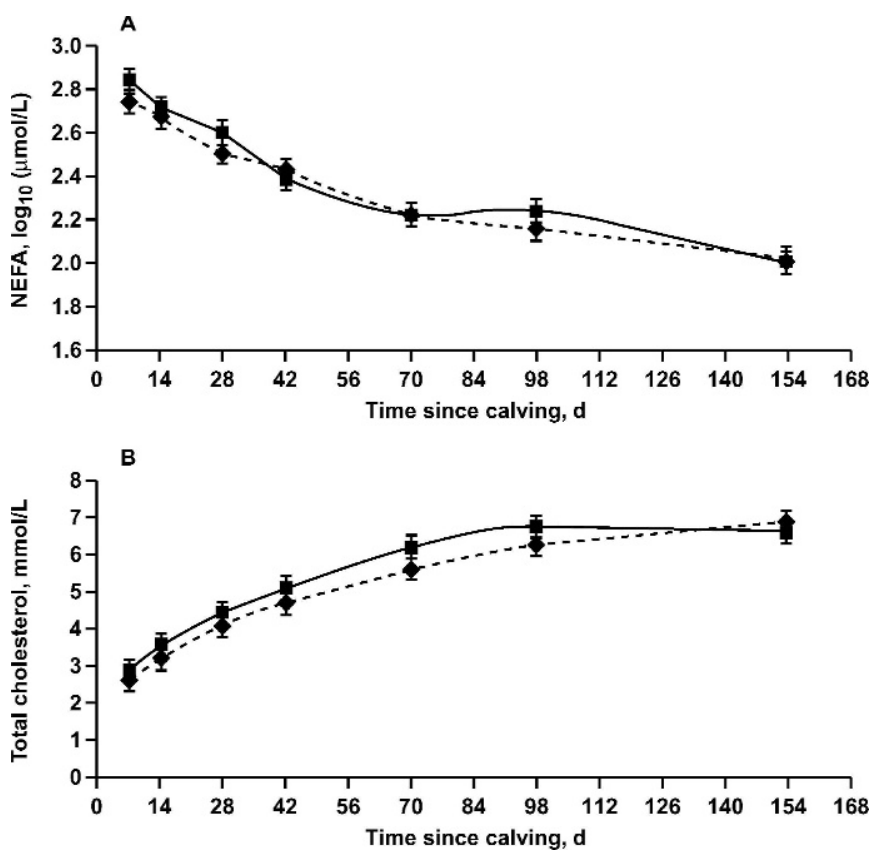

Figure 6. Least squares means $( \pm \mathrm{SE})$ of a) plasma NEFA concentration (reported as $\log _{10} ; \mu \mathrm{mol} / \mathrm{L}$ ) and b) plasma total cholesterol concentration (mmol/L) during the first 154 DIM for cows managed in a traditional milking parlor system (MP; $\bullet$ ) or in an automatic milking system (AMS; $\mathbf{\square}$ ).

$(P<0.001)$ in both groups of cows from 7 to 154 DIM (from 3.6 to $5.0 \mathrm{mmol} / \mathrm{L}, \mathrm{SEM}=0.2$ ), whereas plasma creatinine decreased $(P<0.001)$ from 7 to 98 DIM (from 1.99 to $1.96 \log _{10} \mu \mathrm{mol} / \mathrm{L} ; \mathrm{SEM}=0.007$, corresponding to 97.9 and $90.8 \mu \mathrm{mol} / \mathrm{L}$, respectively).

Plasma concentration of ceruloplasmin was unaffected by milking system (Table 2; Figure 8a). It quickly decreased from 7 to 42 DIM, reaching values $<3.0 \mu \mathrm{mol} /$ $\mathrm{L}$ in both groups. Plasma haptoglobin was unaffected by milking system (Table 2); elevated concentations were observed in both groups at 7 DIM and then decreased in the same way for both groups until 154 DIM. Plasma Zn level was unaffected by both milking systems and DIM (Table 2).

Plasma concentrations of total protein, albumin, and globulin did not differ between groups (Table 2). Plasma albumin increased $(P<0.001)$ with DIM, but there was an interaction $(P<0.001)$ detected between milking system and DIM (Table 2; Figure 8b). Cows in AMS had greater $(P<0.05)$ concentrations of plasma albumin during early lactation (14 and 28 DIM); then, after 70 DIM, plasma albumin in AMS cows remained stable (approximately $36 \mathrm{~g} / \mathrm{L}$ ), whereas plasma albumin in MP cows increased further. Plasma albumin also differed $(P<0.05)$ at $154 \mathrm{DIM}(38.1$ vs. $36.1 \mathrm{~g} / \mathrm{L}$ for $\mathrm{MP}$ and AMS cows, respectively). 
Table 2. Least squares means of blood variables in first-lactation cows milked in the milking parlor or in the automatic milking system (AMS) during early to mid lactation (7 to 154 DIM).

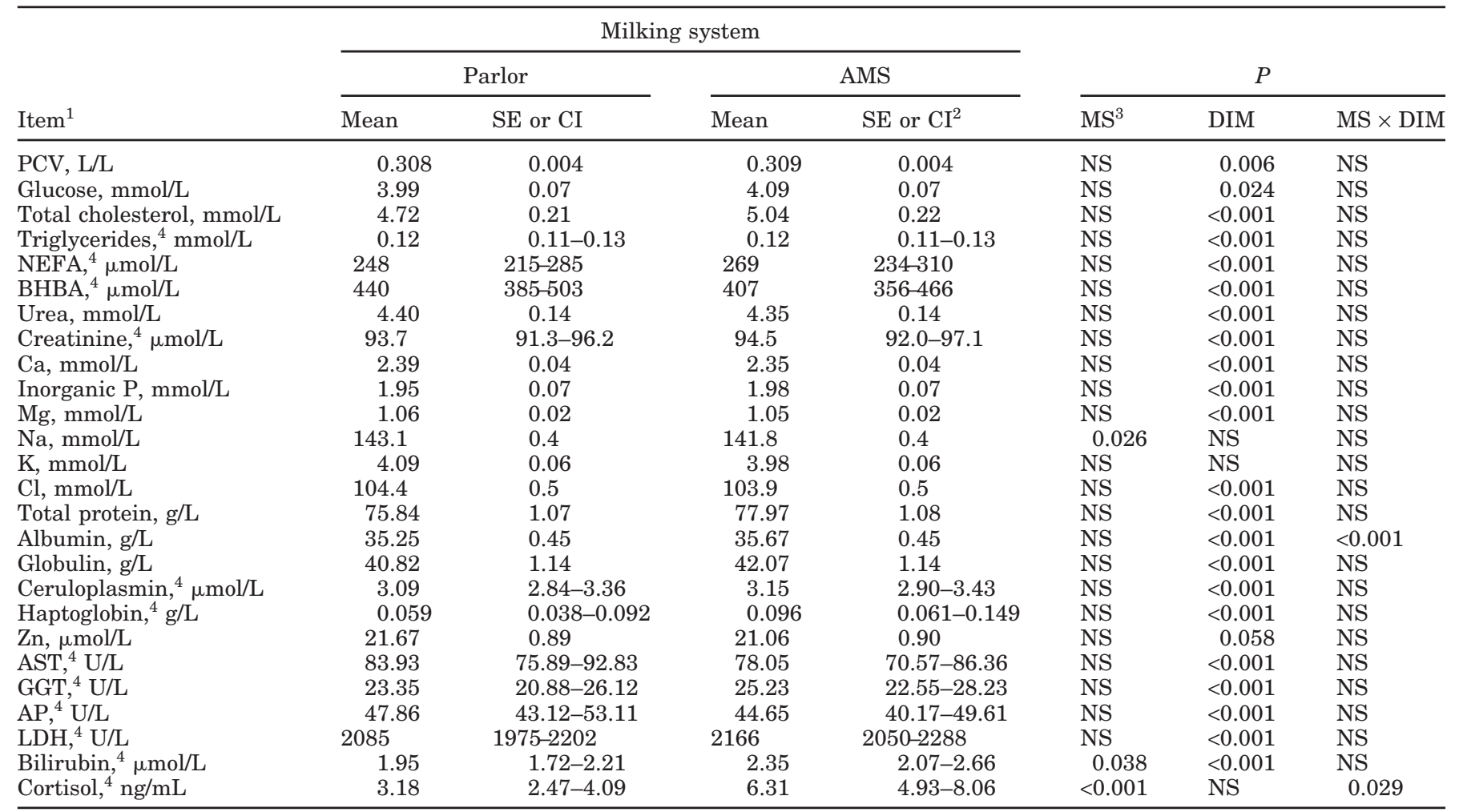

${ }^{1} \mathrm{PCV}=$ Packed cell volume, AST $=$ aspartate aminotransferase, GGT = $\gamma$-glutamyltransferase, $\mathrm{AP}=$ alkaline phosphatase, and LDH = L-lactate dehydrogenase.

${ }^{2} \mathrm{SE}=$ Standard error; $\mathrm{CI}=$ confidence interval at $95 \%$.

${ }^{3} \mathrm{MS}=$ Milking system.

${ }^{4}$ Values are back-transformed in the original measure unit scale after $\log 10$ transformation occurred before statistical evaluation. For these variables, $95 \%$ confidence intervals are reported in lieu of SE.

Plasma GGT and AP activities increased $(P<0.001)$ with DIM and were unaffected by milking system (Table 2). The remaining analyzed enzymes also were unaffected by milking systems (Table 2).

\section{Mineral Metabolism}

Plasma $\mathrm{Ca}$, inorganic $\mathrm{P}$, and $\mathrm{Mg}$ were unaffected by milking system (Table 2), showing the normal dairy cow postpartum pattern. Plasma $\mathrm{K}$ and $\mathrm{Cl}$ also were unaffected by milking system, whereas plasma Na was greater $(P<0.001)$ in MP cows than in AMS cows $(\mathrm{Ta}-$ ble 2).

\section{Basal Plasma Cortisol}

Basal concentrations of plasma cortisol were greater $(P<0.001)$ in AMS cows, and a milking system $\times$ DIM interaction $(P<0.05)$ was detected (Figure 9$)$. Plasma cortisol was greater $(P<0.05)$ in AMS cows than in MP cows at 7 (7.6 vs. $2.8 \mathrm{ng} / \mathrm{mL}$, respectively), 42 (5.2 vs. 1.9 $\mathrm{ng} / \mathrm{mL}$, respectively, 98 ( $8.3 \mathrm{vs} .2 .6 \mathrm{ng} / \mathrm{mL}$, respectively), and 154 DIM (8.2 vs. $3.0 \mathrm{ng} / \mathrm{mL}$, respectively).

\section{DISCUSSION}

\section{Aspects of Metabolic Stress}

The first factor that prompted investigation of the metabolic aspects associated with welfare of cows milked in the AMS was the potentially negative energy balance. Especially in cows during early lactation, negative energy balance could be due to increased milk yield as a result of increased milking frequency (Wiktorsson et al., 2003). It was estimated that AMS leads to increased milk yield ranging between 2 and $11 \%$ (Baines, 2002; de Koning et al., 2002; Wade et al., 2004). Nevertheless, recent studies have confirmed the lack of significant differences in milk yield between MP and AMS for cows, even at greater milking frequencies in AMS (Hopster et al., 2002; Speroni et al., 2004). Our results, as well, do not support a significant increase in milk 

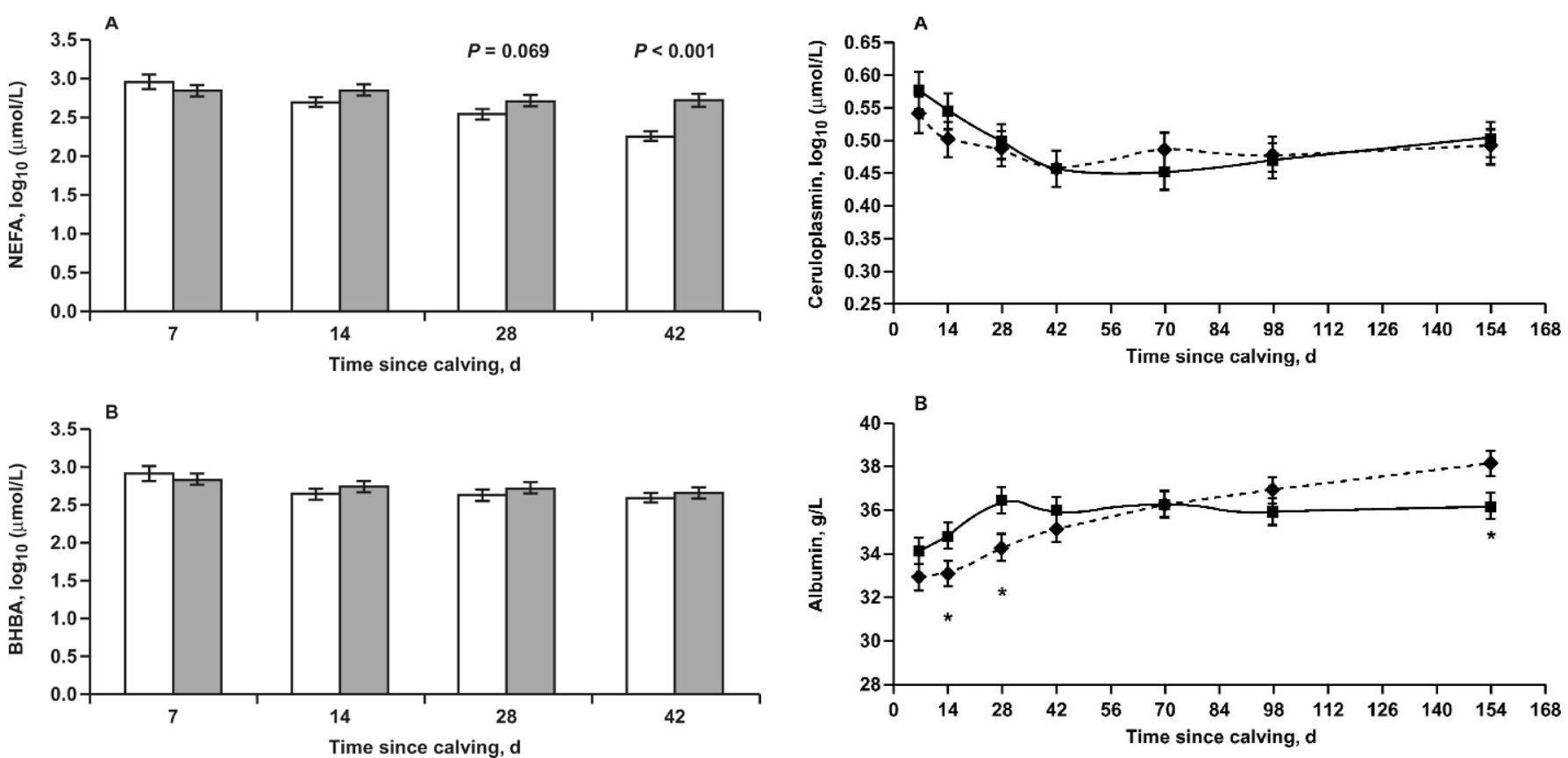

Figure 7. Least squares means ( \pm SE) of a) plasma NEFA and b) plasma BHBA concentration (reported as $\log _{10} ; \mu \mathrm{mol} / \mathrm{L}$ ) during the first 42 DIM for cows managed in an automatic milking system (AMS) when time interval between the last meal and blood sampling was $<3 \mathrm{~h}$ (open bars) or $>3 \mathrm{~h}$ (hatched bars). Significant differences within DIM were highlighted and are reported as the $P$ value above the bars.

yield (both actual milk and ECM) from cows in AMS, thus confirming the most recent literature. A lack of milk yield increase in cows with AMS, even if with an increased milking frequency compared with MP, is an issue already highlighted by Spolders et al. (2004), who observed that primiparous cows had a greater milking frequency than multiparous cows, but this behavior did not imply an increased milk yield. The high milking frequency and the small percentage of milking intervals $>12 \mathrm{~h}$ were probably due to the $2 \times$ daily fetching procedure in our study. Under our experimental conditions, as on many farms, to avoid stress for the cows, the herdsman did not always individually select the cows that had to be fetched. Therefore, when different cows were near, it was possible that some cows milked from $>5 \mathrm{~h}$, but $<12 \mathrm{~h}$, were also milked again, as could take place in practical operating conditions. Nevertheless, the $2 \times$ daily milking activity in the opposite side of the barn at fixed times (starting at 0530 and $1400 \mathrm{~h}$ ), for the management of the MP cows, could be partially responsible for increased activity in AMS cows.

Even if milk yield did not increase, as was true in our study, an increase in negative energy balance might be due to the inability of cows to adapt to a new feeding behavior imposed by a new management system, such as AMS. Results in Figures 2 and 3 could contribute to

Figure 8. Least squares means ( $\pm \mathrm{SE}$ ) of a) plasma ceruloplasmin concentration (reported as $\log _{10} ; \mathrm{ng} / \mathrm{mL}$ ) and b) plasma albumin concentration $(\mathrm{g} / \mathrm{L})$ during the first 154 DIM in primiparous cows managed in a traditional milking parlor system (MP; $\diamond$ ) or in an automatic milking system (AMS; $\mathbf{\square})$. Values sharing an asterisk on the same DIM differ $(P<0.05)$.

a better understanding of our results on milk yield and animal welfare. Cow traffic is an important issue in an AMS. Our management system, having only one TMR distribution per day, could be considered less suitable than other systems that distribute more TMR and match the requirements of better cow traffic to the feeding area. As highlighted in Figure 2, however, our results on daily patterns of cow traffic, especially for the reduced activity in early morning, agree with other reports (Hogeveen et al., 2001; Harms et al., 2002;

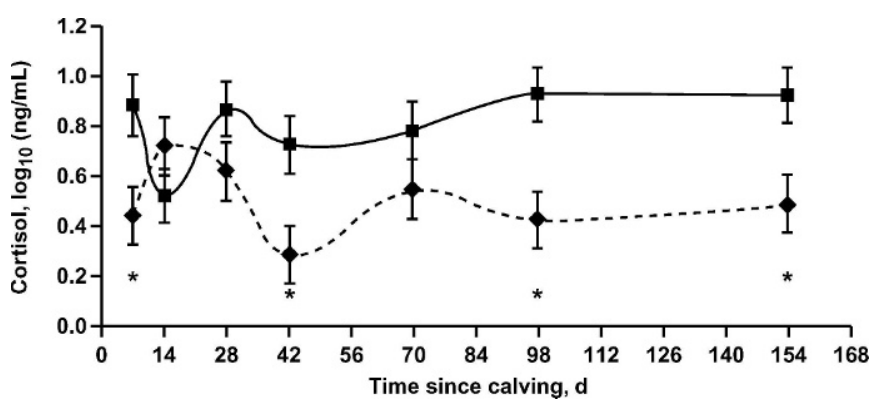

Figure 9. Least squares means $( \pm S E)$ of plasma cortisol concentration (reported as $\log _{10} ; \mathrm{ng} / \mathrm{mL}$ ) during the first $154 \mathrm{DIM}$ in primiparous cows managed in a traditional milking parlor system (MP; $)$ or in an automatic milking system (AMS; $\mathbf{\square})$. Values sharing an asterisk on the same DIM differ $(P<0.05)$. 
Wagner-Storch and Palmer, 2003). Nevertheless, a more negative energy balance did not occur in our study because cows in different milking systems exhibited a similar extent of BCS variation during early lactation (0 to $154 \mathrm{DIM}$ ) and no difference in milk yield. Adaptation to a less suitable feeding procedure might have occurred.

Plasma metabolites related to energy metabolism confirmed the lack of significant differences in body reserve mobilization at the onset of lactation. Plasma concentration of NEFA is widely considered a good marker of body fat mobilization during early lactation (Bertoni et al., 1999). In our study, plasma glucose, triglycerides, NEFA (Figure 6a), and BHBA had similar patterns in MP and AMS cows. The only slight difference (not significant) was the greater plasma NEFA concentration in AMS cows during the first month of lactation when AMS cows had reduced night-time feeding activity (Figure 7a). When the timing of the feeding of the 10 cows in AMS is considered, it was observed that cows with longer feed withdrawal before blood sampling (i.e., those cows with reduced night-time passages through the preselection gate) had greater plasma NEFA, especially at 28 and 42 DIM. Our findings may confirm earlier observations (Bertoni et al., 1994) in which increased plasma NEFA and BHBA were detected before major meals and when the between-meal intervals were longer, particularly $3 \mathrm{wk}$ after calving. A lack of difference in plasma triglycerides and BHBA between MP and AMS cows confirms that AMS did not negatively affect metabolic pathways in cows that could lead to metabolic disorders such as ketosis or fatty liver, according to Wenzel and Nitzschke (2004).

General inflammatory status was not altered by milking system, considering the normal pattern of plasma ceruloplasmin (Figure 8a), haptoglobin, and Zn (Table 2). Ceruloplasmin and haptoglobin increased at calving in both groups. This increase in ceruloplasmin and haptoglobin could have been due to typical inflammatory conditions associated with the puerperium, and values can be considered in the reference range proposed by Bertoni et al. (2000) for lactating cows.

Hepatic ability to synthesize the normal proteins (the so-called negative acute phase proteins) was confirmed to be similar in the 2 milking systems. Our reported albumin (Figure 8b) and total cholesterol (Figure 6b) results are in agreement with the positive acute phase proteins (haptoglobin and ceruloplasmin). Both of these measures were in the range of reference values before calving as reported by Bertoni et al. (2000). Plasma albumin changes in MP and AMS cows had a different pattern during the first $22 \mathrm{wk}$ of lactation. Cows in AMS had greater concentrations of plasma albumin during the first month of lactation. The mean concentration then stabilized at around $36 \mathrm{~g} / \mathrm{L}$ until the end of the experiment (154 DIM). Conversely, plasma albumin in MP cows increased almost linearly from parturition to 154 DIM, when the MP mean was greater than the AMS mean. The differences observed in the first month of lactation were mainly due to the lesser reduction of albumin immediately after calving in the AMS cows than in the MP cows.

The substantial absence of significant effects of milking systems and MS $\times$ DIM on plasma concentrations of urea, creatinine, minerals, and enzymes (Table 2) indicates that the AMS and its related management did not affect protein metabolism, mineral status, or tissue and organ integrity, as detectable by the used methods. The only exception was the plasma Na concentration, which was slightly reduced in AMS cows; however, its values were within the reference range for lactating cows (Bertoni et al., 2000).

\section{Aspects of Psycho-Physiological Stress}

Dairy cows trained for daily collection of a single blood sample by jugular venipuncture is a suitable method of collecting blood if baseline cortisol concentrations need to be determined (Hopster et al., 1999). Backtransformed values of the least square means from ANOVA of cortisol ranged from 1.9 to $8.3 \mathrm{ng} / \mathrm{mL}$ (Table 2; Figure 9) and were greater in AMS cows than in MP cows. The trend was particularly significant and clear at 98 and 154 DIM. In fact, this kind of pattern revealed a difference in plasma cortisol behind an initial adaptation in early stages of lactation. It is sometimes suggested (Bruckmaier et al., 1993) that slightly elevated basal concentrations of cortisol could be a consequence of greater responsiveness because of a chronic stress situation (for AMS cows only, in our case) when managed and immobilized for bleeding. Nevertheless, the response of plasma cortisol to chronic stress is still controversial. For example, although Weiss et al. (2004) considered the elevated cortisol response to an ACTH challenge to indicate an absence of chronic stress, Wiktorsson and Sørensen (2004) suggested that cows with elevated plasma cortisol were those under chronic stress. A possible explanation of the more frequent spikes in the concentrations of cortisol $>5 \mathrm{ng} / \mathrm{mL}$ in AMS cows $(60 \%)$ compared with MP cows $(30 \%)$ could be seen in the different activities occurring in the 1 to $2 \mathrm{~h}$ (including fetching) before blood collection. The MP cows were almost completely quiet, but increased activity of AMS cows was observed. Nevertheless, no correlations were detected between plasma cortisol concentration and time lag from last passage through the preselection gate to blood sampling. Furthermore, our recent 
data (Bertoni et al., 2005) indicated that an interval of $1 \mathrm{~h}$ is sufficient to allow baseline concentrations of cortisol to normalize after usual daily animal handling and manipulations. Another possible explanation could be anxious situation occurring in some cows forced into a system that did not allow more social behavior (Wiktorsson and Sørensen, 2004). This second possibility agrees with the fact that greater basal concentrations of cortisol in some dairy cows are better explained by their lack of comfort in general rather than by the cortisol changes occurring 15 and 30 min after the first manipulation and bleeding (Trevisi et al., 2005).

\section{CONCLUSIONS}

In Italian Friesian first-lactation cows, an increased milk yield in response to an increased milking frequency associated with an AMS is not always confirmed. Therefore, with similar milk yields between MP and AMS, body reserve mobilization was similar, and, as consequence, no differences were detected in plasma metabolites relating to energy metabolism, protein metabolism, mineral metabolism, and liver function. The AMS per se seems not to exert a negative effect on metabolic measures related to nutrient balance. Basal plasma cortisol, a measure of the psycho-physiological stress perceived by the cows, was greater in AMS cows than in MP cows, suggesting a slight chronic stress condition; however, absolute concentrations were within the acceptable range. Finally, further research will be useful to determine how differences between cow traffic systems may lead to different results in milking frequency and milking interval, considering labor requirements and animal welfare associated with forced movement to the AMS for cows not milked at 12-h intervals.

\section{ACKNOWLEDGMENTS}

The authors acknowledge their colleagues (M. Capelletti and L. Migliorati) and everyone (M. Dissegna and P. Re) of the Cremona Dairy Cow Section of the Animal Production Research Institute that made this research possible, with a special thanks to the chief of the farm staff, L. Brusa, for the help afforded.

\section{REFERENCES}

Baines, J. 2002. Managing the change to a robotic milking system. Pages III-9-III-17 in The First North American Conference on Robotic Milking, Wageningen Pers, Wageningen, The Netherlands.

Bertoni, G., L. Calamari, and E. Trevisi. 2000. New criteria for identifying reference values for specific blood parameters in dairy cows. La Selezione Veterinaria 2000(Suppl.):S261-S268.

Bertoni, G., R. Lombardelli, F. Piccioli-Cappelli, and J. Blum. 2002. Basal levels and diurnal variations of some hormones and metabo- lites in blood of dairy cows treated daily with rbST in early and late lactation. Ital. J. Anim. Sci. 1:127-141.

Bertoni, G., F. Piccioli Cappelli, A. Baldi, A. Borghese, E. Duranti, A. Falaschini, A. Formigoni, F. Grasso, N. Lacetera, P. Lupi, A. Meluzzi, W. Pinna, F. Rosi, B. Stefanon, L. Zicarelli, U. Bernabucci, G. Campanile, and M. F. Trombetta. 1999. Guida all'Interpretazione dei Profili Metabolici. Associazione Scientifica di Produzione Animale (ASPA), Università degli Studi di Perugia, Italy.

Bertoni, G., E. Trevisi, and P. Bani. 1994. Metabolic effect of two different lapses without concentrate in early lactating dairy cows. Livest. Prod. Sci. 39:139-140.

Bertoni, G., E. Trevisi, L. Calamari, and R. Lombardelli. 1998. Additional energy and protein supplementation of dairy cows in early lactation: Milk yield, metabolic-endocrine status and reproductive performances. Zootec. Nutr. Anim. 24:17-29.

Bertoni, G., E. Trevisi, R. Lombardelli, and M. Bionaz. 2005. Plasma cortisol variations in dairy cows after some usual or unusual manipulations. Ital. J. Anim. Sci. 4(Suppl. 2):200-202.

Bruckmaier, R. M., D. Schams, and J. W. Blum. 1993. Milk removal in familiar and unfamiliar surroundings: Concentration of oxytocin, prolactin, cortisol and beta-endorphin. J. Dairy Res. 60:449-456.

de Koning, K., Y. van der Vorst, and A. Meijering. 2002. Automatic milking experience and development in Europe. Pages I-1-I-11 in The First North American Conference on Robotic Milking, Wageningen Pers, Wageningen, The Netherlands.

Edmonson, A. J., I. J. Lean, L. D. Weaver, T. Farver, and G. Webster. 1989. A body condition scoring chart for Holstein dairy cows. J. Dairy Sci. 72:68-78.

Harms, J., G. Wendl, and H. Schön. 2002. Influence of cow traffic on milking and animal behaviour in a robotic milking system. Pages II-8-II-14 in The First North American Conference on Robotic Milking, Wageningen Pers, Wageningen, The Netherlands.

Hillerton, J. E., J. Dearing, J. Dale, J. J. Poelarends, F. Neijenhuis, O. C. Sampimon, J. D. H. M. Miltenburg, and C. Fossing. 2004. Impact of automatic milking on animal health. Pages 125-134 in Automatic Milking. A better Understanding. A. Meijering, H. Hogeveen, and C. J. A. M. de Koning, ed. Wageningen Academic Publishers, Wageningen, The Netherlands.

Hogeveen, H., W. Ouweltjes, C. J. A. M. de Koning, and K. Stelwagen. 2001. Milking interval, milk production and milk flow-rate in an automatic milking system. Livest. Prod. Sci. 72:157-167.

Hopster, H., R. M. Bruckmaier, J. T. N. Van der Werf, S. M. Korte, J. Mačuhová, G. Korte-Bouws, and C. G. van Reenen. 2002. Stress responses during milking: Comparing conventional and automatic milking in primiparous dairy cows. J. Dairy Sci. 85:3206-3216.

Hopster, H., J. T. N. Van der Werf, J. H. F. Erkens, and H. J. Blokhuis. 1999. Effects of repeated jugular puncture on plasma cortisol concentrations in loose-housed dairy cows. J. Anim. Sci. 77:708-714.

Knight, C. H., M. Peaker, and C. J. Wilde. 1998. Local control of mammary development and function. Rev. Reprod. 3:104-112.

Martillotti, F., M. Antongiovanni, L. Rizzi, E. Santi, and G. Bittante. 1987. Metodi di analisi per la valutazione degli alimenti di impiego zootecnico. Quaderno metodologico no. 8. IPRA-CNR, Roma, Italy.

Mathijs, E. 2004. Socio-economic aspects of automatic milking. Pages 46-55 in Automatic Milking. A Better Understanding. A. Meijering, H. Hogeveen, and C. J. A. M. de Koning. Wageningen Academic Publishers, Wageningen, The Netherlands.

National Research Council. 2001. Nutrient Requirements of Dairy Cattle. 7th rev. ed. Natl. Acad. Press, Washington, DC.

Olofsson, J., G. Pettersson, and H. Wiktorsson. 2000. Feeding behaviour in an automatic milking system. Pages 189-190 in Proc. Int. Symp. Robotic Milking, Lelystad, The Netherlands. H. Hogeveen and A. Meijering, ed. Wageningen Pers, Wageningen, The Netherlands.

Olofsson, J., and K. Svennersten-Sjaunja. 2004. Improved animal welfare in AMS? Pages 425-426 in Automatic Milking. A Better Understanding. A. Meijering, H. Hogeveen, and C. J. A. M. de Koning, ed. Wageningen Academic Publishers, Wageningen, The Netherlands. 
Rushen, J., L. Munskgaard, P. G. Marnet, and A. M. De Passilé. 2001. Human contact and the effects of acute stress on cows at milking. Appl. Anim. Behav. Sci. 73:1-14.

Smith, J. W., L. O. Ely, W. M. Graves, and W. D. Gilson. 2002. Effect of milking frequency on DHI performance measures. J. Dairy Sci. 85:3526-3533.

Speroni, M., G. Pirlo, and S. Lolli. 2004. Effect of automatic milking systems on milk yield in Italian conditions. J. Dairy Sci. 87(Suppl. 1):57. (Abstr.)

Spolders, M., U. Meyer, G. Flachowsky, and M. Coenen. 2004. Differences between primiparous and multiparous cows in voluntary milking frequency in an automatic milking system. Ital. J. Anim. Sci. 3:167-175.

Trevisi, E., R. Lombardelli, M. Bionaz, and G. Bertoni. 2005. Plasma cortisol level in relationship to welfare conditions in dairy farms. Page 106 in Proc. 56th Annu. Mtg. EAAP.

Wade, K. M., M. A. P. M. van Asseldonk, P. B. M. Berentsen, W. Ouweltjes, and H. Hogeveen. 2004. Economic efficiency of automatic milking systems with specific emphasis on increases in milk production. Pages 62-67 in Automatic Milking. A Better Understanding. A. Meijering, H. Hogeveen, and C. J. A. M. de Koning, ed. Wageningen Academic Publishers, Wageningen, The Netherlands.

Wagner-Storch, A. M., and R. W. Palmer. 2003. Feeding behavior, milking behavior, and milk yields of cows milked in a parlor versus an automatic milking system. J. Dairy Sci. 86:1494-1502.
Weiss, D., S. Helmreich, E. Möstl, A. Dzidic, and R. M. Bruckmaier. 2004. Coping capacity of dairy cows during the change from conventional to automatic milking. J. Anim. Sci. 82:563-570.

Wellnitz, O., and R. M. Bruckmaier. 2001. Central and peripheral inhibition of milk ejection. Livest. Prod. Sci. 70:135-140.

Wenzel, C., and A. Nitzschke. 2004. Study on the incidence of ketosis in dairy cows in an automatic milking system versus a conventional milking system. Pages 184-185 in Automatic Milking. A Better Understanding. A. Meijering, H. Hogeveen, and C. J. A. M. de Koning, ed. Wageningen Academic Publishers, Wageningen, The Netherlands.

Wiktorsson, H., G. Pettersson, J. Olofsson, K. Svennersten-Sjaunja, and M. Melin. 2003. Welfare status of dairy cows in barns with automatic milking. Relations between the environment and cow behaviour, physiologic, metabolic and performance parameters. Report of the EU project "Implication of the introduction of automatic milking on dairy farms" (QLK5-2000-31006) as part of the EU-program "Quality of Life and Management of Living Resources". Deliverable D24, March 2003, 40 pp. Online. Available: http://www.automaticmilking.nl. Accessed Aug. 8, 2003.

Wiktorsson, H., and J. T. Sørensen. 2004. Implications of automatic milking on animal welfare. Pages 371-381 in Automatic Milking. A Better Understanding. A. Meijering, H. Hogeveen, and C. J. A. M. de Koning, ed. Wageningen Academic Publishers, Wageningen, The Netherlands. 